\title{
To intervene or not to intervene: Lessons learned from completion angiography after robotic-assisted coronary bypass surgery
}

\author{
Amalia A. Winters, MD, and Michael E. Halkos, MD, MSc, Atlanta, Ga
}

From the Division of Cardiothoracic Surgery, Department of Surgery, Emory University School of Medicine, Atlanta, Ga.

Disclosures: Dr Halkos is an advisory board member for Medtronic, Inc, and has a patent for a new minimally invasive coronary stabilizer. Dr Winters reported no conflicts of interest.

The Journal policy requires editors and reviewers to disclose conflicts of interest and to decline handling or reviewing manuscripts for which they may have a conflict of interest. The editors and reviewers of this article have no conflicts of interest.

Received for publication March 16, 2020; revisions received March 16, 2020; accepted for publication April 2, 2020; available ahead of print April 11, 2020.

Address for reprints: Amalia A. Winters, MD, 1365 Clifton Rd NE, Building A, Suite A2202, Atlanta, GA 30322 (E-mail: amalia.winters@emory.edu).

JTCVS Techniques 2020;3:190-3

2666-2507

Copyright (C 2020 The Authors. Published by Elsevier Inc. on behalf of The American Association for Thoracic Surgery. This is an open access article under the CC BY-NC-ND license (http://creativecommons.org/licenses/bync-nd/4.0/).

https://doi.org/10.1016/j.xjtc.2020.04.007

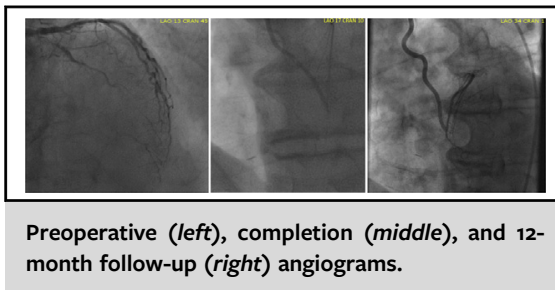

CENTRAL MESSAGE

Conservative management of initial graft failure after roboticassisted CABG in select patients may lead to positive outcomes.

See Commentaries on pages 194 and 196. $\checkmark$ Video clip is available online.

Minimally invasive coronary artery bypass surgery (CABG) is being increasingly performed and robotic-assisted left internal mammary artery to left anterior descending (LIMA-LAD) grafting has been shown to have comparable clinical outcomes to traditional $\mathrm{CABG}^{1}$ while avoiding the morbidity associated with sternotomy. Although completion angiography is not the standard of care for post-CABG patients, we have routinely performed an angiogram in patients after robotic-assisted CABG either in a hybrid room immediately after the procedure, or postoperatively in the catheterization lab. This practice was almost universal in the first several hundred cases and is still routinely done during hybrid revascularization cases. We present a case in which the initial completion angiogram revealed distal LAD occlusion consistent with graft failure; however, the 1-year angiogram showed a widely patent LIMA-LAD anastomosis.

\section{CASE DESCRIPTION}

The patient was an active 80 -year-old man with a history of coronary artery disease status post percutaneous coronary intervention (PCI) to the proximal LAD, hypertension, and atrial fibrillation who presented with exertional chest pain. Echocardiography demonstrated left ventricular ejection fraction $40 \%$. Angiography revealed a chronic total occlusion of his LAD with distal filling via collaterals (Figure 1, Video 1), and we proceeded with roboticassisted CABG. The da Vinci (Intuitive Surgical, Sunnyvale, Calif) robot was used to harvest the LIMA, open the pericardium, and identify the distal LAD target (Video 2). When this was completed, a 3- to 4-cm non-rib-spreading mini-thoracotomy was created for distal anastomosis. The distal LAD was identified and was extremely small, $<1 \mathrm{~mm}$, and was stabilized with the Nuvo off-pump stabilizer (Medtronic Corporation, Minneapolis, Minn). The LIMA-LAD anastomosis was then performed off-pump, manually, using an 8-0 polypropylene suture. A completion angiogram demonstrated poor flow distally, despite intracoronary nitroglycerin; however, there was some retrograde filling of the septal and diagonal vessels (Figure 2, Video 3). Given the small nature of the vessel, the team felt that further attempts at revascularization would be futile. The patient's postoperative course was unremarkable, and he was discharged home on postoperative day 3 . He was seen 12 days postoperatively and was increasing his activity with no angina symptoms, and by 1 month he had resumed all of his previous activities with no angina. Twelve months after surgery a left heart catheterization was completed 


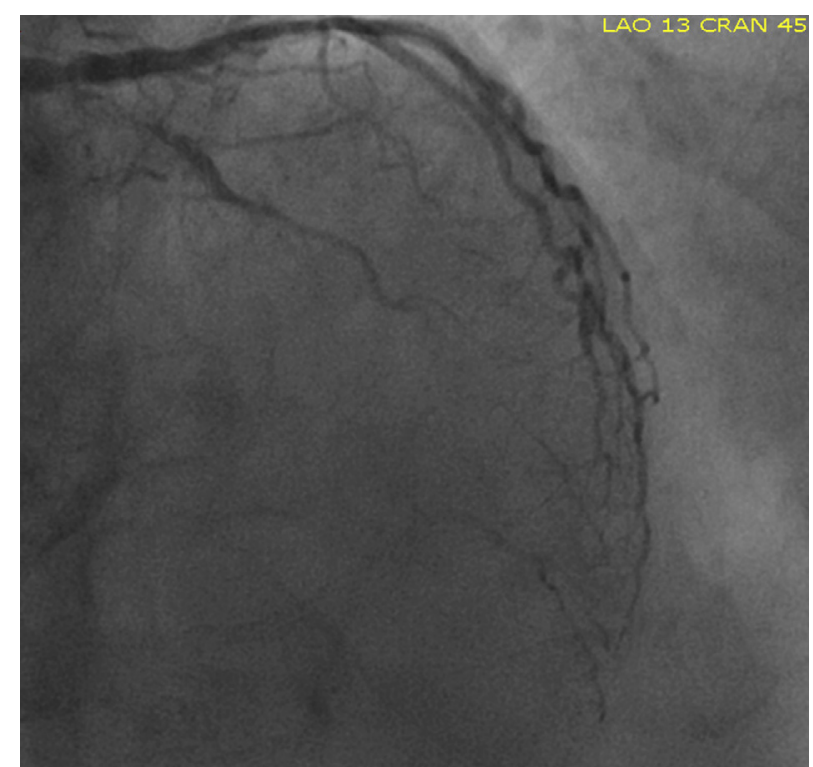

FIGURE 1. Preoperative angiogram, left anterior oblique 13 cranial 45 projection, showing chronic total occlusion of the left anterior descending with distal filling via collaterals.

for clearance before spine surgery, revealing a patent LIMA-LAD graft (Figure 3, Video 4) with good antegrade and retrograde flow. We did not obtain consent specifically for writing this report because no identifiable data was used. In addition, our surgical consent that the patient signed included consent for the use of photographs or videos.

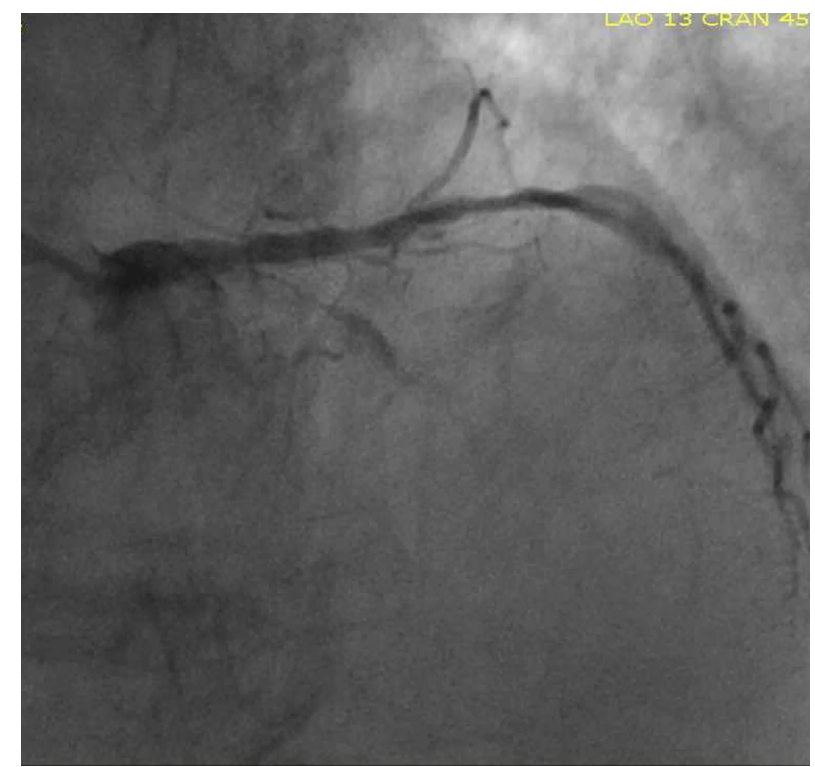

VIDEO 1. Preoperative angiogram, LAO 13 cranial 45 projection, showing chronic total occlusion of the LAD with distal filling via collaterals. Video available at: https://www.jtcvs.org/article/S2666-2507(20) 30198-X/fulltext.

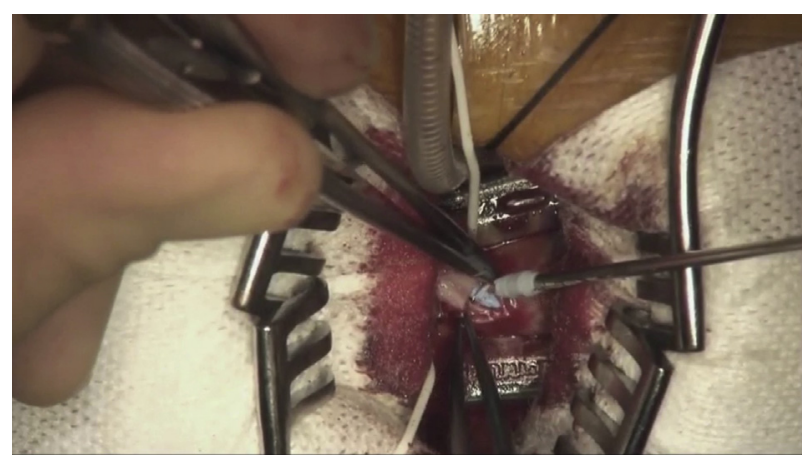

VIDEO 2. Technique for LIMA-LAD anastomosis. After robotic harvest of the LIMA a 3-4-cm mini-thoracotomy is created. The distal LAD is identified and an off pump stabilizer is used. The anastomosis is completed manually, using an 8-0 polypropylene suture. Video available at: https:// www.jtcvs.org/article/S2666-2507(20)30198-X/fulltext.

\section{DISCUSSION}

Completion angiography is not routinely employed by coronary surgeons after CABG in contrast to other cardiovascular procedures, and procedural success is largely determined by subjective surgeon assessment and/or Doppler assessment of grafts in the operating room. Although intraoperative assessment of grafts with transit time flow measurement can provide physiologic assessment of bypass grafts and is currently recommended, there may be a greater incidence of false negatives compared with

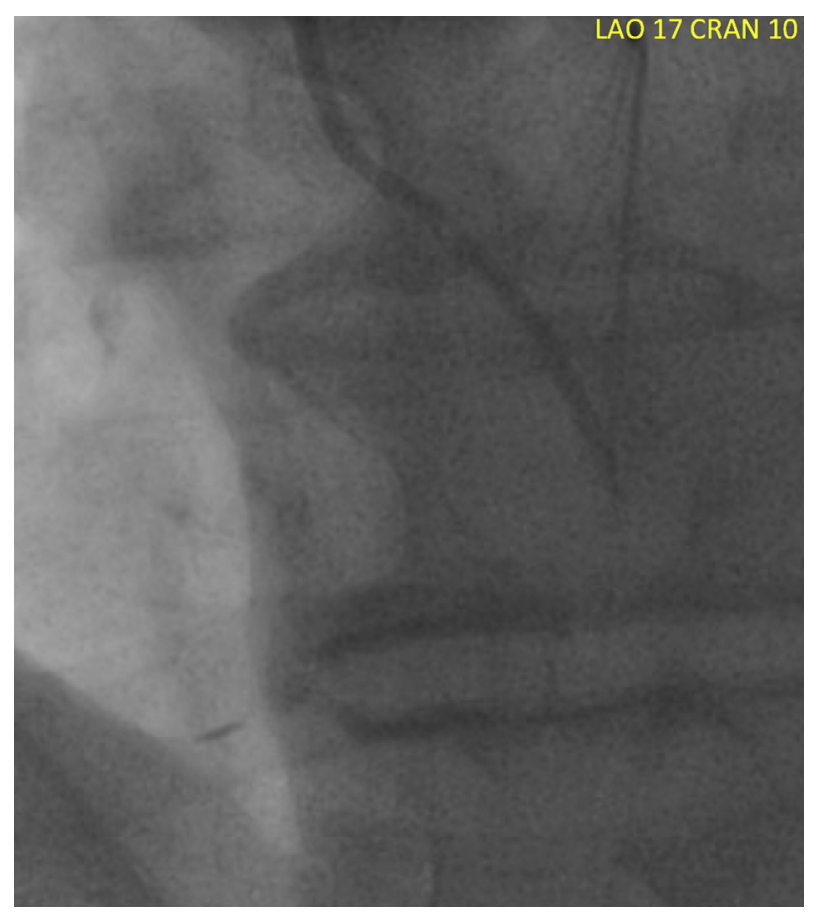

FIGURE 2. Completion angiogram, left anterior oblique 17 cranial 10 projection, after robotic-assisted left internal mammary artery to left anterior descending demonstrating poor flow distally, despite intracoronary nitroglycerin. Some retrograde filling of the septal and diagonal branches is seen. 


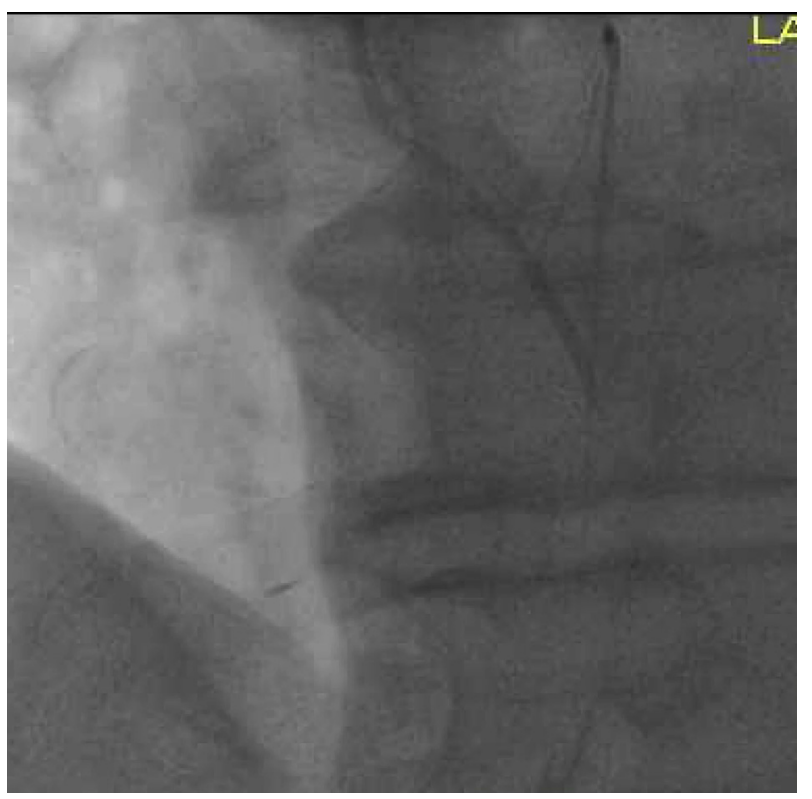

VIDEO 3. Completion angiogram, LAO 17 cranial 10 projection magnified $2 \times$ for comparison, after robotic-assisted LIMA-LAD demonstrating poor flow distally, despite intracoronary nitroglycerin. Some retrograde filling of the septal and diagonal branches is seen. Video available at: https://www.jtcvs.org/article/S2666-2507(20)30198-X/fulltext.

angiography. ${ }^{2}$ Postoperative angiographic graft assessment is typically reserved for patients who have a deviation in expected clinical course or have objective evidence of ischemia. In postoperative CABG patients who undergo

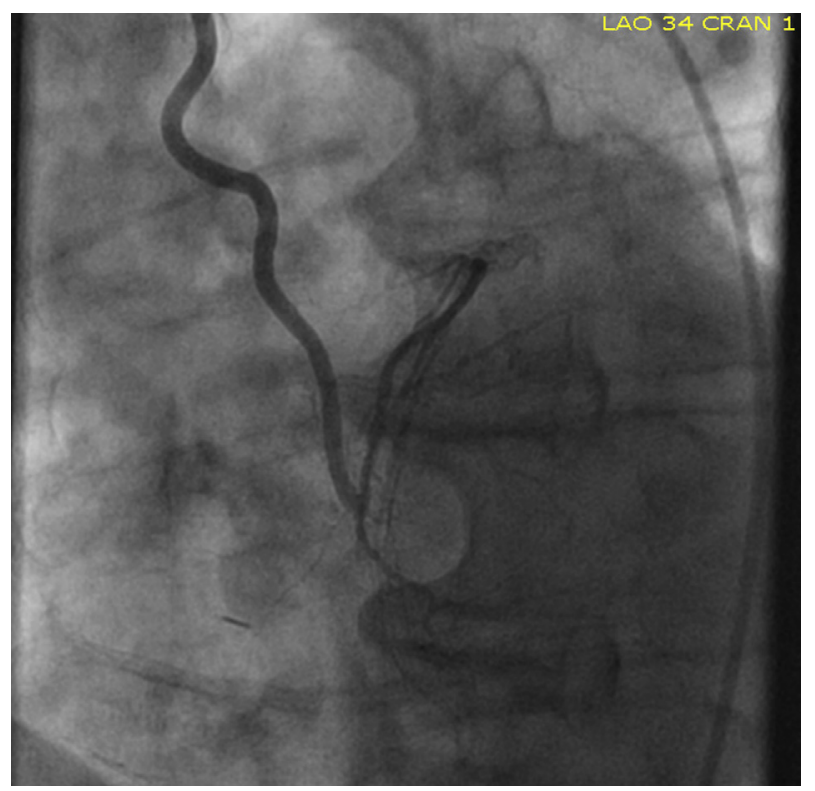

FIGURE 3. Angiogram obtained 12 months postoperatively for cardiac clearance before spine surgery revealing a patent left internal mammary artery to left anterior descending graft with good antegrade and retrograde flow, left anterior oblique 34 cranial 1 projection.

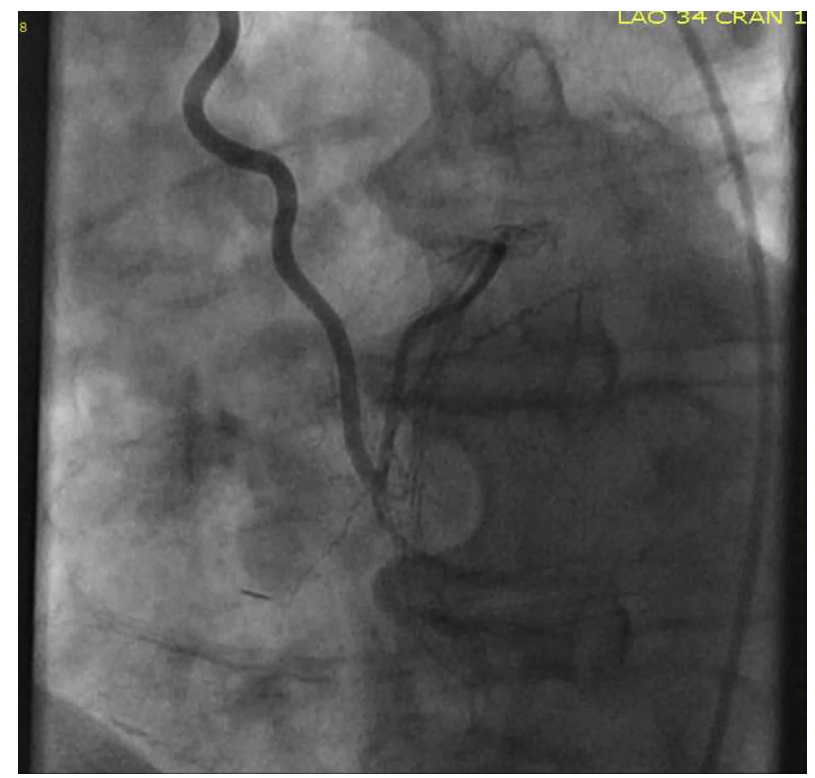

VIDEO 4. Angiogram obtained 12 months postoperatively for cardiac clearance before spine surgery revealing a patent LIMA-LAD graft with good antegrade and retrograde flow, LAO 34 cranial 1 projection. Video available at: https://www.jtcvs.org/article/S2666-2507(20)30198-X/ fulltext.

left heart catheterization for electrocardiogram changes, chest pain, or hemodynamic changes, $69 \%$ have a positive finding related to bypass grafts on imaging. ${ }^{3}$ Previous work from our institution in which the first 199 patients undergoing robotic-assisted LIMA-LAD grafting had routine completion angiography at the time of operation or before discharge found $95 \%$ of bypass grafts to be patent, with 14 graft defects detected. The 5 graft defects identified intraoperatively (3 graft failures, and 2 target vessel errors) were all treated with graft revision during the same operative setting. Of the 9 graft defects identified on postoperative angiography, 6 graft failures were treated with PCI, and 1 patient with graft failure was taken for multivessel CABG. Of the 2 patients with inadvertent diagonal grafting, one received PCI to the LAD, and one did not receive any further revascularization. ${ }^{1}$

Graft patency has been evaluated extensively, primarily with regards to long-term durability. Early graft patency is high, with generally $95 \%$ of arterial and $88 \%$ of vein grafts reported to be patent on early angiography. ${ }^{4}$ Early graft failure is usually due to technical mistakes. However, patientrelated factors such as small distal target vessels or poor runoff, may also play a role. Although the treatment of post-CABG graft failure remains poorly defined, regression of graft stenosis has been described. Izumi and colleagues ${ }^{5}$ described patients with early graft stenosis $>50 \%$ who underwent angiography at an average of 5 years post bypass, and stenosis decreased from $69 \% \pm 13 \%$ to 
$35 \% \pm 20 \%$, suggesting that early graft imperfections in the LIMA to LAD anastomosis may improve without intervention. In the case described in this report, we assumed that this case was a technical failure, until repeat angiography showed a patent LIMA-LAD anastomosis 12 months after surgery.

\section{CONCLUSIONS}

Completion angiography is useful for evaluating initial technical success after robotic-assisted LIMA-LAD grafting. However, conservative management of initial graft failures, especially in patients without objective evidence of ischemia, may lead to positive outcomes.

\section{References}

1. Halkos ME, Liberman HA, Devireddy C, Walker P, Finn AV, Jaber W, et al. Early clinical and angiographic outcomes after robotic-assisted coronary artery bypass surgery. J Cardiovasc Surg. 2014;147:179-85.

2. Walker PF, Daniel WT, Moss E, Thourani VH, Kilgo P, Liberman HA, et al. The accuracy of transit time flow measurement in predicting graft patency after coronary artery bypass grafting. Innovations. 2013;8:416-9.

3. Hultgren K, Andreasson A, Axelsson TA, Albertsson P, Lepore V, Jeppsson A Acute coronary angiography after coronary artery bypass grafting. Scand Cardiovasc J. 2016;50:123-7.

4. Fitzgibbon GM, Kafka HP, Leach AJ, Keon WJ, Hooper GD, Burton JR. Coronary bypass graft fate and patient outcome: angiographic follow-up of 5,065 grafts related to survival and reoperation in 1,388 patients during 25 years. J Am Coll Cardiol. 1996;28:616-26.

5. Izumi C, Hayashi H, Ueda Y, Matsumoto M, Himura Y, Gen H, et al. Late regression of left internal thoracic artery graft stenosis at the anastomotic site without intervention therapy. J Thorac Cardiovasc Surg. 2005;130:1661-7. 